\title{
Cell Therapy for the Treatment of Metabolic Liver Disease: An Update on the Umbilical Cord Derived Stem Cells Candidates
}

\author{
Scheers I., Lombard C., Najimi M. and Sokal E.M. \\ Université Catholique de Louvain, IREC, Laboratory of Pediatric Hepatology and Cell Therapy, Brussels 1200, \\ Belgium
}

\begin{abstract}
Cell therapy has emerged as an attractive alternative to orthotopic liver transplantation for the treatment of liver disease. Among the potential candidates, umbilical cord derived stem cells are of particular interest owing to greater proliferation potential and low immunoreactivity. Previous reports permit to distinguish different cell types that could be generated from cord blood, vessels and cord matrix itself. Wharton Jelly's derived umbilical cord stem cells and cordblood derived mesenchymal stem cells have demonstrated a potential to differentiate into endodermal lineage, including hepatocyte-like cells. In addition, recent studies have underlined their potential to alleviate liver fibrosis and express liver metabolic functions in rodent models.

The present review focuses on the current knowledge on in vitro and in vivo use of these cells for liver cell therapy. We discuss the general characteristics homology between hepatic and umbilical cord derived stem cells and the results of hepatocyte-like differentiation attempts. We finally address the question of future application of these cells for the treatment of liver disease.
\end{abstract}

Keywords: Umbilical cord stem cells, liver regeneration, hepatocyte differentiation.

\section{INTRODUCTION}

Liver transplantation has long been the unique curative treatment for acute or chronic liver diseases. However, the shortage of donor organs and the invasiveness of the procedure in critically ill patients remain major limitations [1]. Recently, cell transplantation has offered a promising alternative approach for liver-based therapies [2-4]. Stem cells originating from various intra and extra-hepatic sources has been investigated for the treatment of hepatic diseases [5-15]. Stem cells are relatively easy to harvest, display an inherent ability to proliferate and demonstrate various differentiation potentials $[16,17]$. Moreover, stem cells present immunotolerogenic features decreasing the risk for graft rejection [18]. Despite encouraging results, the technique is hampered by the restricted number of donors and invasive harvesting techniques. Furthermore, the stem cell yield, their differentiation capacity and in vivo repopulation potential decrease with aging [19]. Umbilical cord mesenchymal stem cells (UCMSC) are an attractive candidate for cell therapy because they are an unexhaustive cell source with a great proliferation potential [20-22]. In addition, because the umbilical cord is discarded at birth, their isolation raises few ethical concerns. These cells also express hepatocyte-like markers [10], which confer them a theoretical advantage for liver cell transplantation. In vitro data and animal studies on hepatocyte-like differentiation of UCMSC are very promising but the demonstration of liver specific functionality, a key task for regenerative medicine application, remains

*Address correspondence to this author at the Cliniques Universitaires Saint-Luc, Department of Pediatrics. Avenue Hippocrate 10, 1200 Brussels, Belgium; Tel: +3227641387; Fax: +3227648909;

E-mail: etienne.sokal@uclouvain.be limited $[10,23,24]$. Further, the ability of UCMSC to repopulate the liver needs to be investigated.

In this review we discuss the general phenotype homology between hepatic and umbilical cord derived stem cells. Secondly, we evaluate the effect of various differentiation protocols on enhancing hepatocyte-like phenotype in UCMSC. Finally we will discuss the steps to be performed for future application of umbilical cord stem cells for the treatment of liver disease.

\section{HEPATOCYTE-LIKE PHENOTYPE CHARACTER- ISTICS OF UCMSC}

In response to various cytokines, the embryonic endoderm initiates its development toward a hepatic specification by generating the primary liver bud [25-27]. This tissue is mainly composed of liver precursors, the hepatoblasts. Early hepatoblasts progressively begin to express characteristic liver genes [28, 29] (such as albumin, alphafetoprotein and HNF-4) while undergoing important growth. From midgestation to perinatal life, hepatoblasts modulate the expression of specific genes to meet the specific needs of each developmental stage. Late hepatoblasts possess bipotential (hepatic and biliary) properties. The cells further differentiate and undergo metabolic and morphologic maturation to finally acquire mature hepatic function during infancy.

As a first proof of their endodermal commitment, UCMSC express some characteristic genes of the definitive endoderm phase (Table 1) such as CXCR-4, Sox 17 and ECadherin. Furthermore, UCMSC express moderate basal mRNA and protein levels of albumin, alpha-foetoprotein, cytokeratin 19 and CD54 (I-CAM) with very low or negative 
levels of CD117 (c-kit), CD56 (N-CAM) and Cyp3A4. The combination of all these markers correlates well with the phenotype of early hepatoblasts. UCMSC also share more mature hepatic features such as cytokeratin 18 (CK18), glucose-6-phosphatase, alpha-1 antitrypsin, connexin-32, phosphoenolpyruvate carboxykinase (PEPCK) and tryptophan-2,3-dioxygenase (TDO). Despite an interesting phenotype, these cell characteristics have to be carefully analyzed, as they do not confer them the status of mature hepatocyte. In the perspective of regenerative medicine, commitment to hepatic lineage is not sufficient per se, as these cells have not yet demonstrated the ability to perform the various metabolic roles of the hepatocyte [41]. Indeed, neither cytochrome activity [10], nor bilirubin conjugation by uridine 5 '-diphosphate-glucuronyltransferase could be detected in UCMSC [42]. Moreover, some of the above mentioned genes are not liver specific and the extent to which some of them are expressed by the liver alone is not clear. Finally, these cells also display mesodermal and ectodermal characteristics possibly associated with many other lineage differentiation potentials [22].

Taken together, UCMSC constitutively express some early stage or more mature hepatic markers and functions, giving them a theoretical advantage for liver tissue repair.
Furthermore, their hepatic commitment could potentially be enhanced by in vitro or in vivo differentiation in response to specific growth factors or host liver environment.

\section{ENHANCING HEPATIC COMMITMENT OF UCMSC AFTER IN VITRO DIFFERENTIATION}

\section{Differentiation Protocols}

Hepatogenic differentiation protocols are performed using a cocktail of factors/cytokines known to be involved in the successive developmental stages leading to mature hepatocytes. To this day, no consensus has been put in place in the literature regarding the protocol that should be used to generate hepatocyte-like cells. The current majority of protocols are performed using fibrosblast growth factor (FGF) and hepatic growth factor (HGF) in early steps. During early embryogenesis, FGF induces competent endoderm cells to an hepatic fate [43] while HGF stimulate hepatoblast proliferation [44]. Later stages utilize Oncostatin M (OSM), which induces, via a STAT-3 mediated signaling cascade, terminal hepatocyte maturation [45]. It remains a matter of debate whether cells should be preferentially differentiated into mature hepatocytes or hepatic progenitors [46]. Indeed, these latter better resist transplantation and

Table 1. Expression of Developmental Hepatic Lineage Markers in UCMSC and Hepatocyte-like Differentiated UCMSC

\begin{tabular}{|c|c|c|c|c|c|c|}
\hline & UCMSC & $\begin{array}{l}\text { Differentiated } \\
\text { UCMSC }\end{array}$ & $\begin{array}{l}\text { Hepatic Stem } \\
\text { Cell }\end{array}$ & Hepatoblast & $\begin{array}{c}\text { Mature } \\
\text { Hepatocyte }\end{array}$ & References \\
\hline CXCR-4 & + & $\mathrm{ND}$ & ND & $\mathrm{ND}$ & + & [30] \\
\hline Sox 17 & + & ND & ND & ND & + & {$[30]$} \\
\hline E-cadherin & + & + & + & + & + & UD, [31] \\
\hline Albumin & + & + & + & ++ & +++ & {$[10,23,24,28]$} \\
\hline Cytokeratin 18 & + & + & ++ & ++ & +++ & {$[10,23,29,32]$} \\
\hline Cytokeratin 19 & + & + & +++ & $++/ /-$ & - & {$[10,24,29,33-35]$} \\
\hline Alpha Fetoprotein & + & + & - & +++ & - & {$[10,23,24,35,36]$} \\
\hline I-Cam (CD54) & $+/-$ & ND & - & ++ & +++ & {$[10,35,37]$} \\
\hline N-Cam (CD56) & - & $\mathrm{ND}$ & +++ & - & - & {$[35,38]$} \\
\hline Сур3А4 & - & + & - & - & ++ & {$[10,35]$} \\
\hline Connexin-32 & + & + & + & ++ & +++ & {$[10,29]$} \\
\hline Alpha-1 antitrypsin & + & + & ND & ++ & +++ & {$[10,29,36]$} \\
\hline $\begin{array}{l}\text { Glucose-6- } \\
\text { phosphatase }\end{array}$ & + & + & ND & ++ & +++ & {$[10,24]$} \\
\hline TAT & - & + & ND & $\mathrm{ND}$ & +++ & {$[10]$} \\
\hline TDO & $+/-$ & + & ND & $+/-$ & ++ & {$[10,24,39]$} \\
\hline PEPCK & + & + & - & + & ++ & {$[10,29]$} \\
\hline HNF-4 & $+/-$ & - & +++ & ++ & ++ & {$[10,29,32,36,40]$} \\
\hline
\end{tabular}

CYP: cytochrome P450, HNF4: hepatic nuclear factor 4, ND: no data, PEPCK: phosphoenolpyruvate carboxykinase, TAT: tyrosine aminotransferase, TDO: tryptophan 2,3dioxygenase, UD: personnal unpublished data. Hepatoblast early // late markers. +/- controversial data in litterature. 
maintain a greater proliferation and repopulation capacity than fully mature differentiated cells.

\section{Assessment of Hepatocyte Differentiation in Vitro}

A critical point in using stem cells for liver cell therapy lies in the acquisition of a sufficient extent of hepatic differentiation to display mature metabolic functions required for effective liver replacement. Classical characterization of differentiated cells includes a comparison of morphological features and the evaluation of mRNA transcript or protein expression. UCMSC, incubated in a specific differentiation medium, display morphological changes evocative of the acquisition of hepatocyte-like features [10]. Spindle shaped UCMSC progressively become more polyhedric, but ultrastructural data is required to further confirm these changes. In most studies, the description of an acquired hepatocytelike phenotype is based on a restricted panel of markers (Table 1). The interpretation of data concerning the extent of hepatic differentiation is difficult using these markers, as authors sometimes observed a dissociation between mRNA or protein expression and maturation of related metabolic function [47]. More interesting -and mandatory- are the concomitant analysis of liver specific functional activities. Altogether, the results of different studies con-firmed that the acquisition of hepatocyte-like phenotype was only partial. Indeed, differentiated cells displayed some early or more mature hepatic markers/functions (such as Cyp3A4, UGT1 and TAT), but lacked expression of molecules such as HNF-4. Moreover, UCMSC maintained native mesenchymal markers, suggesting the persistence of a chimerical phenotype after differentiation.

\section{IN VIVO USE OF UCMSC FOR THE TREATMENT OF LIVER DISEASES}

\section{In Vivo Hepatocyte Differentiation Potential of UCMSC}

While in vitro testings may suggest an hepatocyte-like differentiation potential of UCMSC, the ultimate proof of this capacity relies on the demonstration that cells can repopulate and rescue the liver function in an animal model that mimics human liver disease. Studies analyzing the repopulation and differentiation capacity of UCMSC in vivo are scarce. To our knowledge, no study has used rodent models of metabolic liver failure (Gunn, Nagase Rats; FAH mice,...) to specifically asses the potential of UCMSC to restore liver function. Instead, studies used immunocompromised models (SCID) without liver injury or selective advantage for the injected cells (Table 2). Finally, others used models with induced liver damage $(\mathrm{CCl} 4, \ldots)$. The data obtained using these xenogenic models would further benefit from being complemented by studies using humanized models or human subjects, since cell adhesion, cell-to-cell interactions and differentiation may vary between species [48].

Cell engraftment can be evaluated in vivo by different methods such as fluorescent in situ hybridization, immunostaining, Real Time PCR, etc. As all these techniques carry specific pitfalls, the use of combined methods is largely recommended for accurate evaluation. Thus far, engraftment rates remain low, below 5\%, especially in models that do not provide space or selective advantage for eventual implanta- tion of injected cells (unpublished data). These engraftment numbers seem in most cases insufficient to provide a definitive curative treatment. Different approaches can be considered to favor cell implantation. Regenerative stimulus is very efficient in animal models and clearly was associated with significant improved repopulation. However, the translation of such techniques to humans is difficult. Some methods have already been described in human, such as hepatic irradiation [49], partial hepatectomy or ischemia/ reperfusion injury [50]. Finally, successful hepatic repopulation can be hampered by graft rejection. Recent studies underlined the ability of UCMSC to induce tolerance [51].

\section{Effect of UCMSC on Liver Fibrosis}

Liver fibrosis occurs in response to chronic liver damage induced by a variety of conditions including liver metabolic diseases and autoimmune or viral hepatitis. Chronic hepatic injury of any etiology leads to persistent activation of tissue repair mechanisms mediated by various cytokines and growth factors. Ultimately, this condition drives the progressive accumulation of extracellular matrix (ECM) components [52]. The propensity of MSC to alleviate fibrosis in injured liver has first been described in mice transplanted with bone marrow stem cells [53]. Likewise, rodents in which liver damage was established using CCl4 or TAA injections demonstrated reduced hepatic inflammation and ECM deposition after UCMSC transplantation [39, 54, 55]. Mechanisms mediating these effects are thought to imply the modulation by UCMSC of endogenous secreted factors such as metalloproteinases [56, 57]. These findings however remain controversial, as other authors could not find any effect on hepatic function when rodents were maintained alive for longer periods or in case of extended liver injury (association of hepatotoxic chemicals) [58]. In addition, studies have demonstrated that mesenchymal stem cells display a profibrogenic propensity [59]. Yan et al. [54] have also suggested this fact for UCMSC. Indeed, intravenously infused UCMSC contributed to the myofibroblast population ( $\alpha$ SMA and fibroblast secretory protein-1 positive cells) in mice with $\mathrm{CCl} 4$ induced liver injury.

\section{PERSPECTIVES AND CONCLUSIONS}

Over the last few years, major advances have allowed a better understanding of the different steps and pathways involved in hepatogenesis. In parallel, a great amount of work has been performed in the field of stem cell therapy for regenerative medicine. Umbilical cord mesenchymal stem cells certainly represent a very attractive cell source for liver based treatments as they display several hepatic markers characterizing the sequential steps of liver development. In addition, their differentiation ability to hepatic lineage can be enhanced in vivo and in vitro after culture with hepatogenic factors. A better understanding of the temporal sequence of hepatic differentiation steps will permit the amelioration of in vitro differentiation protocols in the future.

Generating fully mature hepatocytes from stem cells may be an idealistic, extremely difficult task. The extent of hepatic maturation needed for effective cell transplantation greatly depends on the pathology we want to cure. Some conditions such as inborn errors of metabolism are related to 
Table 2. Representative Studies Investigating in Vitro and/or in Vivo Hepatocyte-like Differentiation Ability of UCMSC

\begin{tabular}{|c|c|c|c|c|}
\hline $\begin{array}{l}2 \text { steps - } 5 \text { weeks } \\
\text { DMEM-F12 supplemented } \\
\text { with: } \\
\text { step 1: HGF, FGF, ITS, } \\
\text { Dexa (16days) } \\
\text { step 2: OSM, Dexa, ITS } \\
\text { (16days) }\end{array}$ & $\begin{array}{l}\text { RNA: (PCR) } \\
\text { (+) ALB, AFP, CK19, G6P } \\
\text { (-) TDO } \\
\text { Protein: (IF) } \\
\text { (+) ALB, AFP, CK19 } \\
\text { Function: } \\
\text { (-) LDL uptake, Albumin } \\
\text { secretion, Urea }\end{array}$ & $\begin{array}{l}\text { RNA: } \\
\text { (+) ALB, AFP, CK19, G6P, TDO } \\
(-) / \\
\text { Protein: (IF) } \\
\text { (+) ALB, AFP, CK19 } \\
\text { Function: } \\
\text { (+) LDL uptake, Albumin secretion, } \\
\text { Urea }\end{array}$ & $\begin{array}{l}\text { Host: NOD-SCID } \\
\text { Injury: CCl4 } \\
\text { TRP: } \\
\text { - tail viein } \\
\text { - } 5.10 \text { D cells } \\
\text { Characterization: } \\
\text { RNA: Not tested } \\
\text { Protein: ALB } \\
\text { Function: Not tested }\end{array}$ & Zhao [24] \\
\hline $\begin{array}{l}4 \text { steps - } 5 \text { weeks } \\
\text { IMDM supplemented } \\
\text { with: } \\
\text { step 1: EGF, FGF (2days) } \\
\text { step 2: FGF, HGF, Nico, } \\
\text { ITS (10days) } \\
\text { step 3: HGF, OSM, Nico, } \\
\text { ITS (10days) } \\
\text { step 4: OSM, Dexa, ITS } \\
\text { (10days) }\end{array}$ & $\begin{array}{l}\text { RNA: } \\
\text { (+) ALB, AFP, CX-32, } \\
\text { A1AT, CK19, G6P, PEPCK, } \\
\text { TDO, UGT1A1 } \\
\text { (-) CYP3A4, HNF4, TAT } \\
\text { Protein: (IF-WB) } \\
\text { (+) ALB, AFP, CX-32, } \\
\text { CK19, DPPIV } \\
\text { (-) UGT1 } \\
\text { Function: } \\
\text { (+) G6P, Urea, Cyp3A4, } \\
\text { Glycogen storage }\end{array}$ & $\begin{array}{l}\text { RNA: } \\
\text { (+) ALB, AFP, CX-32, A1AT, } \\
\text { CK19, G6P, PEPCK, TDO, } \\
\text { UGT1A1, CYP3A4, TAT } \\
\text { (-) HNF4 } \\
\text { Protein: } \\
\text { (+) ALB, AFP, CX-32, CK19, } \\
\text { DPPIV, UGT1 } \\
\text { (-) / } \\
\text { Function: } \\
\text { (+) G6P, Urea, Cyp3A4, } \\
\text { Glycogen storage }\end{array}$ & Not tested & $\begin{array}{l}\text { Scheers } \\
{[42]}\end{array}$ \\
\hline
\end{tabular}

Abbreviations: A1AT: alpha 1 antitrypsin, AFP: alphafetoprotein, ALB: albumin, CK19: cytokeratin 19, CC14: carbon tetrachloride, CX-32: connexin 32, CYP: cytochrome P450, D: differentiated cells, Dexa: dexamethasone, DPPIV: dipeptidylpeptidase IV, EGF: epidermal growth factor, FGF: fibroblast growth factor, G6P: glucose-6-phosphatase, HGF: hepatocyte growth factor, HNF4: hepatic nuclear factor 4, IF: immunofluorescence, ITS: insulin-transferrin-selenium, LDL: low density lipoprotein, Nico: nicotinamide, NOD: non obese diabetic, OSM: oncostatin M, PEPCK: phosphoenolpyruvate carboxykinase, SCID: severe combined immunodeficiency, TAT: tyrosine aminotransferase, TDO: tryptophan 2,3-dioxygenase, UD: undifferentiated cells, UGT1: UDP-glucuronyltransferase, WB: western blot.

the deficiency of only one enzyme. In those cases, cells expressing mature hepatic levels of the particular enzyme could be used even in the absence of other hepatic metabolic functions. However, for the treatment of other conditions such as acute hepatic failure, advanced hepatic differentiation will be needed. 
Enhancing cell engraftment and survival will be another critical point on the road to effective clinical application. Study results converge to the conclusion that less than $5 \%$ functional cells should be enough to correct metabolic disease [60]. However, this repopulation rate could be insufficient in case of hepatic failure. Animal models will be useful to better examine UCMSC engraftment in specific conditions. Furthermore, it remains unclear to which extent UCMSC are involved in the reconstitution of hepatic nonparenchymal and metabolically active cells. In vivo UCMSC engraftment and functionality in animal models presenting a metabolic disease remains an unanswered question. Finally, reducing graft rejection can enhance cell survival. Although UCMSC present a poor immunogenic profile [24], it is unclear if immunosuppressive therapy is needed to avoid graft rejection.

Recent research has demonstrated the long-term in vitro and in vivo tumorigenic safety of UCMSC. Extensive analysis of cell karyotype and modulation of cell cycle regulation genes during culture remained normal over a long period of time [42]. However, other safety issues concerning cell administration route, clotting risk, etc. have to be further assessed.

Finally, studies performed on liver cirrhosis models have demonstrated promising anti-inflammatory and anti-fibrogenic properties of UCMSC. In depth studies of the mechanisms involved in these processes will certainly bring new insights for the targeted treatment of liver cirrhosis. Although previous work has underlined the ability of UCMSC to differentiate into hepatocyte-like cells in vivo, further investigations should be performed to better understand the effective role of these cells in helping functional liver repair.

Overall, UCMSC present interesting characteristics for cell based therapies. Further improvements regarding cell distribution, engraftment and differentiation capacity with demonstration of acquired metabolic functions in vivo will help to unveil the real potential and place of UCMSC in clinical liver based therapies.

\section{ACKNOWLEDGEMENTS}

IS: drafting the manuscript

LC, MN, ES: revising it critically for important intellectual content

\section{CONFLICT OF INTEREST}

The authors report that no conflict of interest exists.

\section{REFERENCES}

[1] Sterling RK, Fisher RA. Liver transplantation. Living donor, hepatocyte, and xenotransplantation. Clin Liv Dis 2001; 5: 431-60

[2] Fox IJ, Chowdhury JR, Kaufman SS, Goertzen TC, Chowdhury NR. Treatment of the Crigler-Najjar syndrome type I with hepatocyte transplantation. N Engl J Med 1998; 338: 1422-6.

[3] Smets F, Najimi M, Sokal EM. Cell transplantation in the treatment of liver disease. Pediatr Transplant 2008; 12: 6-13.

[4] Stephenne X, Najimi M, Sibille C, Nassogne MC, Smets F, Sokal EM. Sustained engraftment and tissue enzyme activity after liver cell transplantation for arginosuccinate lyase deficiency. Gastroenterology 2006; 130: 1317-23.

[5] Lee $\mathrm{KD}$, Kuo $\mathrm{TK}$, Whang-Peng $\mathrm{J}$, et al. In vitro hepatic differentiation of human mesenchymal stem cells. Hepatology 2004; 40: 1275-84.

[6] Hong SH, Gang EJ, Jeong JA, et al. In vitro differentiation of human umbilical cord blood-derived mesenchymal stem cells into hepatocyte-like cells. Biochem Biophys Res Commun 2005; 330: 1153-61.

[7] Seo MJ, Suh SY, Bae YC, Jung JS. Differentiation of human adipose stromal cells into hepatic lineage in vitro and in vivo. Biochem Biophys Res Commun 2005; 328: 258-64.

[8] Espejel S, Roll GR, Mc Laughlin KJ, et al. Induced pluripotent stem cell-derived hepatocytes have the functional and proliferative capabilities needed for liver regeneration in mice. J Clin Invest 2010; 120: 3120-6.

[9] Chien CC, Yen BL, Lee FK, et al. In vitro differentiation of human placenta-derived multipotent cells and into hepatocyte-like cells. Stem Cells 2006; 24: 1759-68.

[10] Campard D, Lysy PH, Najimi M, Sokal EM. Native umbilical cord matrix stem cells express hepatic markers and differentiate into hepatocyte-like cells. Gastroenterology 2008; 134: 833-48.

[11] Najimi M, Khuu ND, Lysy PA, et al. Adult-derived human liver mesenchymal-like cells as a potential progenitor reservoir of hepatocytes? Cell Transplant 2007; 16: 717-28.

[12] Zheng YB, Gao ZL, Xie C, et al. Characterization and hepatogenic differentiation of mesenchymal stem cells from human amniotic fluid and human bone marrow: a comparative study. Cell Biol Int 2008; 32: 1439-48.

[13] Lavon N, Benvenisty N. Study of hepatocyte differentiation using embryonic stem cells: Prometheus revisited? J Cell Biochem 2005; 96: 1193-202.

[14] Lysy PA, Smets F, Sibille C, Najimi M, Sokal EM. Human skin fibroblasts: from mesodermal to hepatocyte-like differentiation. Hepatology 2007; 46: 1574-85

[15] Stadtfeld M, Graf T. Assessing the role of hematopoietic plasticity for endothelial and hepatocyte development by non-invasive lineage tracing. Development 2005; 132: 203-13.

[16] Dominici M, Le Blanc K, Mueller I, et al. Minimal criteria for defining multipotent mesenchymal stromal cells. The Internationa Society for Cellular Therapy position statement. Cytotherapy 2006; 8: 315-7.

[17] Lysy PA, Campard D, Smets F, Najimi M, Sokal EM. Stem cells for liver tissue repair: current knowledge and perspectives. World J Gastroenterol 2008; 14: 864-75.

[18] Le Blanc K, Ringden O. Immunomodulation by mesenchymal stem cells and clinical experience. J Intern Med 2007; 262: 509-25.

[19] Stenderup K, Justesen J, Clausen C, Kassem M. Aging is associated with decreased maximal life span and accelerated senescence of bone marrow stromal cells. Bone 2003; 33: 919-26.

[20] Wang HS, Hung SC, Peng ST, et al. Mesenchymal stem cells in the Wharton's Jelly of the human umbilical cord. Stem Cells 2004; 22: 1330-7.

[21] Karahuseyinoglu S, Cinar O, Kilic E, et al. Biology of stem cells in human umbilical cord stroma: in situ and in vitro surveys. Stem Cells 2007; 25: 319-31.

[22] Troyer DL, Weiss ML. Concise review: Wharton's jelly-derived cells are a primitive stromal cell population. Stem Cells 2008; 26: 591-9.

[23] Zhang YN, Lie PC, Wei X. Differentiation of mesenchymal stromal cells derived from umbilical cord Wharton's jelly into hepatocytelike cells. Cytotherapy 2009; 11: 548-58.

[24] Zhao Q, Ren H, Li X, et al. Differentiation of human umbilical cord mesenchymal stromal cells into low immunogenic hepatocyte-like cells. Cytotherapy 2009; 11:414-26.

[25] Zhao R, Duncan SA. Embryonic development of the liver Hepatology 2005; 41: 956-67.

[26] Zaret KS. Regulatory phases of early liver development: paradigms of organogenesis. Nat Rev Genet 2002; 3: 499-511.

[27] Lemaigre FP. Mechanisms of liver development: concepts for understanding liver disorders and design of novel therapies. Gastroenterology 2009; 137: 62-79.

[28] Schmelzer E, Wauthier E, Reid LM. The phenotypes of pluripotent human hepatic progenitors. Stem Cells 2006; 24: 1852-8. 
[29] Turner WS, Schmelzer E, McClelland R, Wauthier E, Chen W, Reid LM. Human hepatoblast phenotype maintained by hyaluronan hydrogels. J Biomed Mater Res B Appl Biomater 2007; 82: 156-68.

[30] Nekanti U, Dastidar S, Venugopal P, Totey S, Ta M. Increased proliferation and analysis of differential gene expression in human Wharton's jelly-derived mesenchymal stromal cells under hypoxia. Int J Biol Sci 2010; 6: 499-512.

[31] Roelandt P, Pauwelyn KA, Sancho-Bru P, et al. Human embryonic and rat adult stem cells with primitive endoderm-like phenotype can be fated to definitive endoderm, and finally hepatocyte-like cells. Plos One 2010; 5: e12101.

[32] La Rocca G, Anzalone R, Corrao S, et al. Isolation and characterization of Oct-4+/HLA-G+ mesenchymal stem cells from human umbilical cord matrix: differentiation potential and detection of new markers. Histochem Cell Biol 2009; 131: 267-82.

[33] Desmet VJ, Van Eyken P, Sciot R. Cytokeratins for probing cell lineage relationships in developing liver. Hepatology 1990; 12: 1249-51.

[34] Stosiek P, Kasper M, Karsten U. Expression of cytokeratin 19 during human liver organogenesis. Liver 1990; 10: 59-63.

[35] Zhang L, Theise N, Chua M, Reid LM. The stem cell niche of human livers: symmetry between development and regeneration. Hepatology 2008; 48: 1598-607.

[36] Lazaro CA, Croager EJ, Mitchell C, et al. Establishment, characterization, and long-term maintenance of cultures of human fetal hepatocytes. Hepatology 2003; 38: 1095-106.

[37] Conconi MT, Burra P, Di Liddo R, et al. CD105(+) cells from Wharton's jelly show in vitro and in vivo myogenic differentiative potential. Int J Mol Med 2006; 18: 1089-96.

[38] Weiss ML, Medicetty S, Bledsoe AR, et al. Human umbilical cord matrix stem cells: preliminary characterization and effect of transplantation in a rodent model of Parkinson's disease. Stem Cells 2006; 24: 781-92.

[39] Lin SZ, Chang YJ, Liu JW, et al. Transplantation of human Wharton's Jelly-derived stem cells alleviates chemically induced liver fibrosis in rats. Cell Transplant 2010; 19: 1451-63.

[40] Inada M, Follenzi A, Cheng K, et al. Phenotype reversion in fetal human liver epithelial cells identifies the role of an intermediate meso-endodermal stage before hepatic maturation. J Cell Sci 2008; 121: $1002-13$

[41] Hengstler JG, Brulport M, Schormann W, et al. Generation of human hepatocytes by stem cell technology: definition of the hepatocyte. Expert Opin Drug Metab Toxicol 2005; 1: 61-74.

[42] Scheers I, Lombard C, Paganelli M, et al. Umbilical cord matrix stem cells maintain a stable immunophenotype and do not undergo transformation during long-term in vitro culture. In Press.

[43] Jung J, Zheng M, Goldfarb M, Zaret KS. Initiation of mammalian liver development from endoderm by fibroblast growth factors. Science 1999; 284: 1998-2003.

[44] Zaret KS. Hepatocyte differentiation: from the endoderm and beyond. Curr Opin Genet Dev 2001; 11: 568-74.
[45] Kamiya A, Kinoshita $\mathrm{T}$, Ito $\mathrm{Y}$, et al. Fetal liver development requires a paracrine action of oncostatin $\mathrm{M}$ through the gp130 signal transducer. EMBO J 1999; 18: 2127-36.

[46] Sancho-Bru P, Najimi M, Caruso M, et al. Stem and progenitor cells for liver repopulation: can we standardize the process from bench to bedside? Gut 2009; 58: 594-603.

[47] Zaret KS. Regulatory phases of early liver development: paradigms of organogenesis. Nat Rev Genet 2002; 3: 499-511.

[48] Maerckx C, Campard D, Tondreau T, et al. Hepato-biliary profile of candidate liver progenitor cells isolated from healthy rat liver. World J Gastroenterol. [In Press].

[49] Gupta S, Gorla GR, Irani AN. Hepatocyte transplantation: emerging insights into mechanisms of liver repopulation and their relevance to potential therapies. J Hepatol 1999; 30: 162-70.

[50] Grompe M, Laconi E, Shafritz DA. Principles of therapeutic liver repopulation. Sem Liv Dis 1999; 19: 7-14.

[51] Weiss ML, Anderson C, Medicetty S, et al. Immune properties of human umbilical cord Wharton's Jelly-derived cells. Stem cells 2008; 26: 2865-74.

[52] Friedman SL. Mechanisms of hepatic fibrogenesis. Gastroenterology 2008; 134: 1655-69.

[53] Sakaida I, Terai S, Yamamoto N, et al. Transplantation of bone marrow cells reduces CCl4-induced liver fibrosis in mice. Hepatology 2004; 40:1304-11

[54] Yan Y, Xu W, Qian H, et al. Mesenchymal stem cells from human umbilical cords ameliorate mouse hepatic injury in vivo. Liver Int 2009; 29: 356-65.

[55] Tsai PC, Fu TW, Chen YM, et al. The therapeutic potential of human umbilical mesenchymal stem cells from Wharton's Jelly in the treatment of rat liver fibrosis. Liver Transplant 2009; 15: 48495 .

[56] Mias C, Lairez O, Trouche E, et al. Mesenchymal stem cells promote matrix metalloproteinase secretion by cardiac fibroblasts and reduce cardiac ventricular fibrosis after myocardial infarction. Stem Cells 2009; 27: 2734-43.

[57] Rabani V, Shahsavani M, Gharavi M, Piryaei A, Azhdari Z, Baharvand $\mathrm{H}$. Mesenchymal stem cell infusion therapy in a carbon tetrachloride-induced liver fibrosis model affects matrix metalloproteinase expression. Cell Biol Int 2010; 34: 601-5.

[58] Carvalho RL, Quintanilha LF, Dias JV, et al. Bone marrow multipotent mesenchymal stromal cells do not reduce fibrosis or improve function in a rat model of severe chronic liver injury. Stem Cells 2008; 26: 1307-14

[59] di Bonzo LV, Ferrero I, Cravanzola C, et al. Human mesenchymal stem cells as a two-edge sword in hepatic regenerative medicine: engraftment and hepatocyte differentiation versus profibrogenic potential. Gut 2008; 57: 223-31.

[60] Nussler A, Konig S, Ott M, et al. Present status and perspectives of cell-based therapies for liver diseases. J Hepatol 2006; 45: 144-59.

Received: February 28, 2011

Revised: May 13, 2011

Accepted: June 12, 2011

(C) Scheers et al.; Licensee Bentham Open.

This is an open access article licensed under the terms of the Creative Commons Attribution Non-Commercial License (http://creativecommons.org/ licenses/by-nc/3.0/), which permits unrestricted, non-commercial use, distribution and reproduction in any medium, provided the work is properly cited. 